\title{
The impact of energy resources on social development in Russia
}

\author{
N. Didenko \& D. Skripnuk \\ Department of International and Regional Economics, \\ St. Petersburg State Polytechnical University, Russia
}

\begin{abstract}
Various countries are endowed with energy resources differently. It is supposed that the availability of energy resources is a sign of a nation's wealth. However, countries that are richly endowed with energy resources can actually differ significantly from each other in living standards. It is interesting to know how the production and export of energy resources impact on the social sphere of developing countries. There is an existing interest in investigating this problem because of the importance of the production and export of energy resources, for maintaining the standard of living of a population.

This article analyzes the impact of the production and export of energy resource, namely of oil on the social sphere in Russia. The Russian fuel and energy sector accounts for about $30 \%$ of industrial output, for $32 \%$ of consolidated revenues, for $54 \%$ of the federal budget, for $54 \%$ of exports and for $45 \%$ of foreign exchange earnings in Russia. Social services are estimated by the following indicators: the index of Gini, the average wage in the country and the population's savings. The main advantage of using the Gini coefficient is that it measures inequality. Wage also performs important functions; the motivation of employees and providing a living wage. The savings of the population are at the crossroads of interests for citizens and the state. Based on data from 1990 to 2012 on the dynamics of oil production in Russia, the dynamics of oil exports from Russia and the dynamics of the social sphere in Russia are analyzed using the production model. Estimation of the coefficients and their significance has been assessed using statistical methods. By taking the logarithm of the production function; three multiple regression equations that represent the models of the economic processes for the Gini coefficient, average wage and savings were obtained. According to the results of econometric analysis,
\end{abstract}


conclusions about the significance of production, exports and the prices of oil for the development of the social sphere are made.

Keywords: the Gini coefficient, the average wage, the population's savings, oil production in Russia, oil exports from Russia, oil price.

\section{Introduction}

Various countries are endowed with energy resources differently. It is thought that the availability of energy resources is a sign of a nation's wealth. However, countries that are richly endowed with energy resources actually differ significantly from each other in living standards. For example, oil-rich Norway has high social development indicators, including a high Human Development Index (HDI). The USA, having quite rich oil reserves, also exhibit high rates of social development. Nigeria, belonging to the major oil-producing countries, has low GNP per capita and low social development indicators. We see a paradoxical type of social inequality in which some countries do not have equal chances and opportunities of using their natural resources. Speaking at the annual meeting of the American Economic Association in 1989, the renowned economic historian David S. Landes asked the fundamental question of economic growth and development: "Why are we so rich and they so poor?" [1]. Landes asked of course a general question about the wealth and poverty of countries. We are interested in both the wealth and poverty of the country affected by the availability and use of natural resources. Specifically, how can the production and export of energy resources affect the social development of the nation? For empirical estimates of Russia's social development, oil is one of the most important energy resources for all the economies that were chosen.

\section{General information about the fuel and energy sector and its significance}

The fuel and energy complex (FEC) is an essential structural component of the economy of Russia and is one of the key factors for the support of the country's life. The complex produces more than a quarter of Russia's industrial output, significantly affecting the country's budget.

Currently FEC is one of the stable industrial complexes in the Russian economy. It determines the state and prospects of development of the national economy by constituting about one fourth of GDP, one third of the industrial output and revenues of the consolidated budget of Russia, about half of the federal budget revenues, exports and foreign exchange earnings.

Fully providing themselves with fuel and energy resources, Russia is a major exporter of fuel and energy; they make about $60 \%$ of its export potential.

Russia has always been considered as one of the leading energetic states of the world. In the world production and consumption of energy, Russia is accounting for $23 \%$ of gas, about $10 \%$ of oil (including gas condensate) and almost $6 \%$ of coal and electricity. The role of energy resources in the formation of a sustainable energy supply will continue in $21^{\text {st }}$ century. 
In Russia, the value of the fuel and energy complex is particularly high. Firstly, because of the huge resource potential: $2.4 \%$ of the world's population and $13 \%$ of the area of the world, it has $12-13 \%$ of the forecasted energy resources, including more than $12 \%$ of proven oil reserves, more than $30 \%$ of gas reserves and more than $11 \%$ of proven coal reserves [2]. Secondly, it has unique industrial, scientific and technical human resources. Thirdly, FEC is very important due to climatic conditions under which the supply of energy resources and the economy of the country is a vital factor for the existence of entire regions.

The structure of the Russian economy in the 1990 developed in the opposite direction as the global trends. The weight of raw materials, including energy resources, in the structure of world GDP has declined steadily. In developed countries, GDP growth accounts mainly to the manufacturing industry (especially in the modern high-tech production) and services.

In Russia, it is the opposite situation. The fuel and energy sector accounts for about $30 \%$ of industrial output, for $32 \%$ of consolidated revenues, for $54 \%$ of the federal budget, for $54 \%$ of exports and for $45 \%$ of foreign exchange earnings in Russia. Over the past 10 years the share of high value-added industries has decreased in the industrial structure [3].

\section{Indicators of social development}

Traditionally, education, health, housing and social insurance is included in the social sphere. Development of this sector is estimated by a sufficiently large number of indicators. Some of the principals are also important for social development. Of all the varieties of principles and indicators we have identified the following: the principle of social justice, the average income in the country and national savings.

Social justice is selected due to the fact that justice is one of the main aspects of the development of the society. If people feel justice in the country, this country is more cohesive and it affects the development of the country. Economic science proposes the evaluation of social justice with the help of statistical methods, and specifically by the Gini index.

Stratification of a society can be assessed in several ways. One of them is the calculation of the decile coefficient. This is a simple proportion of the average income of $10 \%$ of the richest people to the income of $10 \%$ of the poorest people. The decile coefficient in Russia is nearly 16 . The exception is the US, where the coefficient is higher. Explanation for this phenomenon is that the dissatisfaction with their financial standing among Americans is not directed against the state but against oneself. This is mentality of the American nation - your fault if you are poor. As for Russia, according to the Global Wealth Report 2012 hundred billionaires dispose nearly $30 \%$ of all private assets, while the world average is about $1 \%$.

The Gini coefficient is used by statistical agencies of the United Nations for the analysis of income dynamics over time within a country, and therefore one can see if inequality is increasing or decreasing. 
The main advantage of using the Gini coefficient is that it shows the inequality using the ratio analysis, rather than using generalized parameters such as national income per capita, or GDP per capita.

If the Gini coefficient increases with GDP, the majority of the population remains poor.

The Gini index for Russia is obtained on the basis of official data from "Rosstat". However "Rosstat" does not consider factors that decrease the value of the index: the payment of shadow wages to their employees and shady bribes to officials by some Russian business in some cases.

The Gini coefficient for Russia is close or greater than that of Brazil's (57\%), because real income of the powerful minority is very largely compared to the income of the poor, who constitute the majority (millions of dollars for the rich and one hundred dollars per month for each of forty million senior citizens and people with disabilities).

It is also possible to regard the earnings as an indicator or a measure of social development. Wage performs three functions:

- motivation of employees of all levels and job skills;

- $\quad$ providing a living wage for groups of the least skilled or for those who lost modern profession;

- $\quad$ raising the level of employees' skills in accordance with the needs of the economy.

Savings of the population occupy a special place among economic phenomena, because they are at the crossroads of interests of citizens and the state. On the one hand, savings are an important indicator of quality of life directly related to consumption, income and expenditures of the population. On the other hand, savings of the population represent a valuable resource for economic development, a source of investment and lending to the economy.

Thus, the index Gini, the average wage in the country and the savings of the population are selected as indicators for evaluating social development.

\section{Selection of the production model}

Choosing the type of the production model was based primarily on the results of the preliminary content analysis, according to the theoretical assumptions about the nature of the development process being studied, i.e. impact of production, export and prices of oil on selected indicators that assess the social sphere.

Analysis of the relationship between social development indicators and natural resources is estimated by the following model of the form:

$$
y=A D^{B} E x^{C} e^{\sigma p}
$$

where $y$ - resulting indicator; $D$ - extraction of oil; $E x$ - export of oil; $P$ - price of oil.

To estimate this model we used Statistica 8.0. This model is a power function. Therefore for simplicity, the equation has been transformed to obtain a linear equation. The transformed equation is as follows:

$$
\ln y=\ln A+B \ln D+C \ln E x+(\sigma p)
$$


An important component of the building an econometric model is the selection of factors that significantly affect the studied parameters. Thus these factors are included in the model being developed. Optimal set of factors was determined on the basis of qualitative and quantitative analysis. All factors has been included in the model whose impact should be taken into account when considering impact of energy resources on the social development, i.e. production, exports and the price of oil. In the next steps feasibility of incorporating of each factor into the model has been tested with the help of formal statistical methods.

First of all, the factors have been examined based on correlation between them. A high correlation between the factors results in unreliable estimates of the model parameters due to multicollinearity issues. In order to estimate single impacts of the indicators one or more factors has been omitted. Of the two correlated factors the one which is more correlated with the other has been excluded.

Criteria for including factors in the model are the degree of their isolated influence on the resulting indicator, defined by the coefficient of correlation.

The method of least squares has been used to estimate the coefficients. Closeness of the relationship of the studied phenomena has been assessed with the coefficient of determination $\mathrm{R}^{2}$. At each step the regression model was constructed and the significance of factors was tested. The analysis shows that the residuals tend to a normal distribution. To test the significance of the factors Student's t test and Fisher criterion have been used. Assessment of the quality of the constructed model was also carried out by using Durbin-Watson statistics, showing the presence of autocorrelation in the residuals.

\section{Empirical specification and regression results}

\subsection{Relationship between GINI index and production, exports and prices of oil}

Statistical data in Table. 1 shows that the Gini coefficient increased in the past twenty years. During the same period Russia's GDP also grew. But if the Gini coefficient increases with GDP, the majority of the population remains poor. In the same period of time oil production and exports also tended to increase. One can also see upward price trends except in 2009.

In accordance with the methods of the analysis model (1) was transformed by taking the logarithm:

$$
\ln G I N I=B \ln D+C \ln E x+(\sigma p)
$$

The correlation analysis shows that the strongest relationship is between GINI index and exports of oil (0.59), then between GINI index and the price of oil (0.3). Finally the relationship between GINI index and production of oil is negative $(-0.1)$. 
The regression results show that $\mathrm{R}^{2}$ is 0.95 . Calculated value of Fisher coefficient is greater than the critical level, suggesting the importance of the equation in total. All coefficients of the model are statistically significant. The equation is:

$$
\ln G I N I=6,25-0,89 \ln D+0,51 \ln E x+(0,00036 p)
$$

We can say that an increase in the exports and the price of oil is associated with an increase in the GINI coefficient. However and increase in production of oil is associated with a decrease in the GINI coefficient.

\subsection{Relationship between the average wage and production, exports and prices of oil}

The relationship between the average wage and natural resources is being analyzed in the following section. Statistical information from 1990 to 2012 is presented in Table. 1. Table 1 indicates that there are two specific periods of time, with different trends in average wages in Russia: between 1992 and 1998 and between 1999 and 2012. The first period is characterized by high volatility and the second by an increasing trend.

Table 1: Production, exports and the price of oil, GINI coefficient, average wage, savings, 1990-2012. The production of oil is measured in millions of tons, exports of oil are measured in millions of tons, price of oil is measured in US dollars per ton, wage is measured in US dollars, savings are measured in billions of US dollars [5]

\begin{tabular}{|c|c|c|c|c|c|c|}
\hline Year & Production & Exports in & Price & GINI & Wage & savings \\
\hline 1990 & 516 & 109 & 304 & 24,0 & 409,22 & na \\
\hline 1991 & 462 & 117 & 255 & 26,0 & 101,36 & na \\
\hline 1992 & 399 & 128 & 236 & 29,0 & 23,96 & na \\
\hline 1993 & 354 & 127 & 199 & 40,0 & 140,67 & na \\
\hline 1994 & 318 & 126 & 182 & 41,0 & 66,85 & 116,85 \\
\hline 1995 & 307 & 122 & 189 & 38,7 & 130,38 & 110,83 \\
\hline 1996 & 301 & 121 & 224 & 38,7 & 181,39 & 103,90 \\
\hline 1997 & 306 & 123 & 200 & 39,0 & 176,58 & 88,86 \\
\hline 1998 & 303 & 137 & 126 & 39,4 & 80,22 & 46,49 \\
\hline 1999 & 305 & 134 & 170 & 40,0 & 73,69 & 55,33 \\
\hline 2000 & 324 & 144 & 273 & 39,5 & 82,33 & 93,90 \\
\hline 2001 & 348 & 165 & 223 & 39,7 & 115,00 & 101,11 \\
\hline 2002 & 380 & 190 & 218 & 39,7 & 139,00 & 99,10 \\
\hline 2003 & 421 & 228 & 259 & 40,3 & 179,00 & 125,15 \\
\hline 2004 & 459 & 260 & 342 & 40,9 & 234,00 & 182,33 \\
\hline 2005 & 470 & 253 & 440 & 40,9 & 297,00 & 237,95 \\
\hline 2006 & 481 & 248 & 497 & 41,5 & 404,00 & 304,45 \\
\hline 2007 & 491 & 259 & 531 & 42,2 & 529,00 & 391,91 \\
\hline 2008 & 488 & 243 & 728 & 42,1 & 691,00 & 539,38 \\
\hline 2009 & 494 & 248 & 428 & 42,1 & 658,00 & 281,57 \\
\hline 2010 & 495 & 251 & 561 & 42,1 & 711,41 & 409,15 \\
\hline 2011 & 508 & 245 & 665 & 41,7 & 797,00 & na \\
\hline 2012 & 518 & 240 & 699 & 42,0 & 802,00 & na \\
\hline
\end{tabular}


The following regression has been estimated:

$$
W=A D^{B} E x^{C} e^{\sigma p}
$$

where W - wage; D - extraction of oil; Ex - export of oil; P - price of oil.

The correlation coefficients between variables used in the model above show the following. The strongest correlation is between wage and the price of oil (0.84). The correlation between the production of oil and wage is 0.73 . The weakest correlation is between exports and wage $(0.7)$. The equation is as follows:

$$
\ln W=-1,4+0,64 \ln D+0,32 \ln E x+(0,0033 p)
$$

The regression analysis shows that $\mathrm{R}^{2}$ is 0.85 . Calculated value of the Fisher coefficient is greater than the critical level, suggesting the importance of the equation in total. But significant is only one indicator - the price. This could be because of the multicollinearity issues caused by the high correlation between the explanatory variables. In order to be able to assess the single effect of the indicators we exclude the insignificant indicators from the regression equation leaving a model with two explanatory variables. In the changed models two indicators remain insignificant. Thus we exclude again one of the explanatory variables. Therefore a model with price of oil as a single explanatory remains for the analysis. The equation is as follows:

$$
W=e^{3,82+0,0044 p}
$$

The results of the regression with two explanatory variables show that $\mathrm{R}^{2}$ is equal to 0.84 . Calculated value of the Fisher coefficient is greater than the critical level, indicating the importance of the equation in total. Price is a statistically significant indicator. We can say that the growth of oil prices is associated with an increase in wages.

\subsection{Relationship between savings and production, exports and prices of oil}

The following section analyzes the relationship between savings and natural resources. Statistical information from 1990 to 2012 is shown in Table 1.

The following regression has been estimated:

$$
S=A D^{B} E x^{C} e^{\sigma p}
$$

where S - savings; D - extraction of oil; Ex - export of oil; $\mathrm{P}$ - price of oil.

The correlation analysis shows that the correlation between savings and the price of oil is 0.896 , between the savings and production of oil is 0.89 and between savings and exports of oil is 0.8 .

Results of the regression analysis show that $\mathrm{R}^{2}$ is 0.98 . Calculated value of the Fisher coefficient is greater than the critical level, suggesting the importance of the equation in total. All coefficients of the model are statistically significant. Equation is as follows:

$$
\ln S=-17.7+0,64 \ln D-3,11 \ln E x+(0,0017 p)
$$

An increase in production and price of oil is associated with an increase in savings. An increase in exports however is associated with a decrease in savings. 


\section{Conclusion}

This paper analyzes the impact of production and export of energy resources represented by oil on the social sphere in Russia. The social sphere has been estimated by the following indicators: GINI coefficient, the average wage in the country and the population's savings. Based on data from 1990 to 2012 the paper analyzed the dynamics of oil production in Russia, the dynamics of oil exports from Russia and dynamics of social sector in Russia.

To analyze the relationship between the GINI coefficient, the average wage and savings and the production and export of energy resources the following model has been estimated:

$$
y=A D^{B} E x^{C} e^{\sigma p}
$$

where $\mathrm{y}$ - resulting indicator; D - production of oil; Ex - exports of oil; $\mathrm{p}$ - price of oil.

Estimation of the coefficients and their significance has been assessed using statistical methods. By taking the logarithm of the production function three multiple regression equations that represent the models of the economic processes for the GINI coefficient, average wage and savings, were obtained. Method of least squares has been used to estimate the coefficients. Closeness of the relationship of the studied phenomena has been assessed with the coefficient of determination $\mathrm{R}^{2}$. The quality of the regression coefficients was checked by using the t-statistic for a certain level of significance.

Assessment of the quality of the constructed model was also carried out by using Durbin-Watson statistics, showing the presence of autocorrelation in the residuals. Criterion values are in the range of $[0,4]$. According to the results of econometric analysis conclusions about the significance of production, exports and prices of oil for the development of the social sphere are made. Results of the analysis imply that an increase in oil production and the price of oil is associated with an increase in household savings, and an increase in exports of oil is associated with a decrease in savings. Higher GINI coefficient is associated with increases in oil exports and raising prices of oil, while lower GINI coefficient is associated with increasing oil production. Higher oil prices are associated with increasing wages.

Although exports of natural resources negatively affect savings, the results of empirical estimates indicate that increase in the rate of growth of consumption of energy resources contributes to the social development of the country. Thus, the empirical estimates confirm that the availability of natural resources contributes to the social development of the country. Therefore the resource-rich countries should pursue policies to reduce their exports and, consequently, stimulating the growth of their domestic consumption. Probably such a policy is not possible for small countries with very large reserves of natural resources and in the international division of labor, specializing in the export of natural resources (Kuwait, UAE, and Saudi Arabia). Russia, with the scale of its economy, a welldeveloped industrial infrastructure and an historical focus on manufacturing rather than services, can implement policies to stimulate the domestic consumption of natural resources. 


\section{References}

[1] Charles I. Jones. Introduction to economic growth, $2^{\text {nd }}$ ed., W.W. Norton \& Company Ltd: New York and London, p. 1, 2001.

[2] www.istu.edu/docs/education

[3] www.ruseconomy.ru/nomer13_200310/ec02.html

[4] Didenko N.I. International Economics, Feniks: Rostov on Don, pp. 45-49, 2007.

[5] http://data.worldbank.org/indicator/SI.POV.GINI, http://opoccuu.com/wages .htm, http://www.indexmundi.com/facts/russia/gross-savings 